\title{
Disturbance of Skin Sensation
}

National Cancer Institute

\section{Source}

National Cancer Institute. Disturbance of Skin Sensation. NCI Thesaurus. Code C34549.

Disruption of the normal functioning of the sensory nerves in the skin. 